\title{
OS VALORES CRISTÃOS MEDIEVAIS EVIDENCIADOS NA BUSCA DA FELICIDADE E SUA RELAÇÃO COM A PRÁTICA PEDAGÓGICA CONTEMPORÂNEA: O CASO DE OITO PROFESSORES DA CIDADE DE SÃO PAULO - UMA PESQUISA DE CAMPO
}

\section{ARTIGO DE REVISÃO}

HOYLER, Sandra Helena Loureiro ${ }^{1}$

CHIACCHIO, Simon Skarabone Rodrigues ${ }^{2}$

HOYLER, Sandra Helena Loureiro, CHIACCHIO, Simon Skarabone Rodrigues. Os valores cristãos medievais evidenciados na busca da felicidade e sua relação com a prática pedagógica contemporânea: 0 caso de oito professores da Cidade de São Paulo - uma pesquisa de campo. Revista Científica Multidisciplinar Núcleo do Conhecimento. Ano 04, Ed. 02, Vol. 04, pp. 40-53. Fevereiro de 2019. ISSN: 2448-0959.

\section{RESUMO}

Neste artigo serão apresentados os valores cristãos medievais difundidos e propagados por Santo Agostinho no período em que buscava pela felicidade. Seguirá exibindo uma amostra do imaginário dos docentes das escolas pública e privada do Estado de São Paulo de como estes valores destacados pelo teólogo são representados no exercício da prática pedagógica no ambiente escolar. Por fim, farse-á uma análise reflexiva sobre a relevância destes valores na prática docente no

\footnotetext{
${ }^{1}$ Mestre, Professor titular no Departamento de Pedagogia do Centro Universitário Estácio.

2 Pós-Doutor em Administração de Empresas, Doutor em Educação Currículo, Mestre em Gestão de Saúde e Meio Ambiente e Mestre em Ciências, Professor Titular no Departamento de EaD do Senac-SP.
} 
contexto contemporâneo. Este trabalho será apoiado pelos pensamentos do teólogo Santo Agostinho em sua obra La Vida Feliz.

Palavras-Chave: Santo Agostinho, valores cristãos, prática pedagógica, discentes, docentes.

“...nós não temos problemas, temos oportunidades"

Siegfried Hoyler

\section{INTRODUÇÃO}

Entre tantos educadores da literatura que enfocaram a questão dos valores, o teólogo Santo Agostinho contribuiu no entendimento de que o mundo além de ser movido pelo dinheiro é também movido por valores que constituem a tessitura social que rege o comportamento das pessoas.

Este trabalho apresentará os valores cristãos medievais difundidos e propagados por Santo Agostinho no período em que buscava pela verdade, logo a felicidade. Após, procederá com uma amostra do imaginário dos docentes das escolas pública e privada do Estado de São Paulo de como estes valores destacados pelo teólogo são representados no exercício da prática pedagógica no ambiente escolar. Por imaginário, entende-se suas idéias, pensamentos e sentimentos enraizados no íntimo de cada um. Examinar-se-á os valores destacados por Santo Agostinho e também os princípios éticos: diálogo, respeito, justiça e solidariedade, visto que todos emolduram de um modo geral a visão da areté. A palavra areté que mais tarde veio a ser traduzida como virtude é empregada nos poemas homéricos para definir a excelência de qualquer tipo. O corredor veloz exibe a areté dos pés; o filho supera o pai em todos os tipos de areté, sendo atleta, soldado e intelectualmente. (MACINTYRE, 2001, apud, REIS 2001:14)[3] 
$\mathrm{Na}$ busca pela felicidade Santo Agostinho destacou o valor da sabedoria, o valor da medida da alma que ajudará o homem sábio a encontrar o equilíbrio na vida e o valor das virtudes. Por fim, o teólogo destacou o maior de todos valores considerados por ele - o bem permanente, imutável e eterno - Deus.

Verificar-se-á que o homem tem liberdade e livre arbítrio para dirigir sua vida para fazer suas escolhas e norteá-la positivamente ou não. Cada indivíduo no percurso da vida mostra os valores que possui independente do tamanho de suas ações.

Segundo Aranha (1993), a preocupação com os valores, a axiologia (do grego axios, que significa valor), não se ocupa dos seres, mas das relações que se estabelecem entre os seres e o sujeito que os aprecia. A proposição sobre valores sempre esteve ligada a uma das significativas áreas da filosofia, a saber: a ética. Esta surgiu ante as questões que a levaram a se reportar às suas próprias origens, "[...] ética significa, em primeiro lugar, o ramo da filosofia que fundamenta cientifica e teoricamente a discussão sobre valores, opções (liberdade), consciência, responsabilidade, o bem e o mal, o bom e o ruim etc." (NOSELLA, 2008:256). Posteriormente, a areté representou a discussão principal do pensamento grego.

O homem sendo um ser social, pertencente à uma sociedade, é responsabilizado por aquilo que ele constrói. Desta maneira, vivendo em sociedade, está sujeito a obedecer a valores e normas impostas pelos homens. Contudo, sabemos que existem pessoas sempre prontas a tirar proveito dos outros. São muitos os tipos de atitudes reprovadas em nossa sociedade, como também, há muitos exemplos de atitudes boas.

Nessas contradições e impasses ressaltam-se quais são os valores éticos e morais que mais têm importância para cada ser humano. Olhando por este prisma, entendese quão importante é o papel da educação. À ela cabe garantir a qualidade de ensino, num desafio de todas as horas, num compromisso para a vida inteira. Sua escala de valores vai influir e alterar a percepção e a vida das crianças e jovens. À educação cabe velar pelo equilíbrio da razão e emoção entre a família, a escola e a sociedade contribuindo para a harmonia e o alcance da felicidade. 


\section{DIÁLOGO DE SANTO AGOSTINHO NA OBRA LA VIDA FELIZ - VALORES DESTACADOS}

Santo Agostinho pergunta: "parece cosa evidente que nosotros constamos de cuerpo y alma?"[4], ou seja, parece evidente que o homem é constituído de corpo e de alma? Para o teólogo a alma é a parte mais nobre do homem. Sobre esta questão, no livro I do Contra acadêmicos, ele afirmava que se o homem quer ser feliz deveria viver com o que há de melhor em si mesmo, que, segundo ele, é a parte da alma que exerce poder em todas as outras: mente ou razão. Dizia ainda, que o supremo bem do homem, bem este, que proporciona a felicidade, está na mente do homem sábio.

Desde a sua conversão ao cristianismo Santo Agostinho se propôs a demonstrar que a fé e a razão tinham fortes ligações para que o homem encontrasse a felicidade. Pois se o homem sábio tivesse fé encontraria a verdade eterna. No entanto, afirmou que a fé é precedida por certo trabalho da razão. Ainda que as verdades da fé não sejam demonstráveis, ou seja, passíveis de prova, é possível mostrar o acerto de ser crer nelas, logo, esta tarefa é da razão. A razão está duplamente ligada a fé. É preciso entender para crer e crer para entender (Agostinho, 1999).

Em vista disto surge a seguinte questão: o homem sábio será feliz quando procura pela verdade? Santo Agostinho responde que "na verdade, como desejamos ser felizes, seja no alcance, seja na atenta investigação da verdade, colocando de lado todas as coisas, se desejamos ser felizes é preciso procurá-la. “[5].

Santo Agostinho afirma que se o homem realmente quer ser feliz é preciso esforçarse para encontrar tal felicidade.. Fundamentado pela ferramenta da verdade o homem passará a ter novos conhecimentos podendo desta maneira contestar e argumentar acerca da própria verdade. Antes de Santo Agostinho converter-se ao cristianismo conheceu o maniqueísmo, o ceticismo e o neoplatônismo, e então continuou sua busca pela felicidade até encontrar o verdadeiro sentido da vida nas palavras atribuídas ao próprio Cristo, que, segundo a tradição Cristã, disse no Evangelho de Mateus: "Pedi e dar-se-vos-à; buscai e encontrareis; batei e abrir-se-vos-á. Porque 
aquele que pede, recebe, o que busca, encontra e ao que bate se abre." (Mt, 7:7- 8). Com efeito, de posse da verdade, junto veio à felicidade e a paz interior.

Para Santo Agostinho o sábio que busca os preceitos de Cristo - as verdades que estão nas escrituras bíblicas - tem direito de sentir-se bem-aventurado e feliz. O salmo 1 nos traz o segredo da felicidade. Ele identifica as passivas bem-aventuranças. $O$ salmo 2 registra: felizes os que se refugiam no Senhor [v.12] e o Salmo 34 [v.8] repete a mesma certeza. O salmo 32, feliz é aquele cuja iniqüidade é perdoada [v.1]. O salmo 4, feliz é aquele que acode ao necessitado. O salmo 119, feliz é aquele que guarda as prescrições do Senhor, e as busca de todo o coração [v.2] (Hoyler, 1987).

Já ordenado bispo de Hipona, Santo Agostinho diz que sábio é aquele que possui a sabedoria, mas que pela virtude o homem encontraria a verdade e, conseqüentemente, a felicidade.

O teólogo traça uma diferenciação entre o sábio e o ignorante ${ }^{[6]:}$. Sábio é aquele que possui a alma mais completa e perfeita que o ignorante. Os ignorantes possuem as origens dos hábitos ruins, a malignidade que é originária da palavra nada, ou seja, esterilidade. Por sua vez, o sábio possui virtudes como a temperança, a parcimônia e a sobriedade. Neste sentido, o sábio tem a alma fértil, diferentemente dos ignorantes que tem a alma estéril, ou seja, não produz. Portanto, a alma do sábio é perfeita: ora, ao que é perfeito nada falta. Ele se servirá de tudo que é necessário ao seu corpo e estiver ao seu alcance. Em caso contrário, a falta desses bens não conseguirá abatêlo. Posto que a característica do sábio é ser forte, e o forte, nada teme. [...] logo, o sábio evitará a morte e o sofrimento quando lhe for possível e conveniente. [...] Tudo o que ele faz, será conforme as prescrições da virtude e da divina lei da sabedoria. ${ }^{[7]}$

Em vista disto entende-se que a felicidade do sábio vem depois que ele possue a virtude, pois, estando com ela nada faltará. Em contrapartida, o ignorante fatalmente será infeliz, que nas palavras de Santo Agostinho é dito como o miserável. Contudo, é possível haver meio termo entre felicidade e infelicidade? O pensador esclarece com outra pergunta, no capítulo IV, verso 24, de La Vida Feliz: "-¿ ¿Te parece que hay término medio entre un vivo y un muerto?", ou seja, pode haver meio termo entre o 
vivo e o morto? Para Santo Agostinho não existe meio termo entre a felicidade e a infelicidade. A felicidade pertence ao homem virtuoso e o alimento da sua alma é a sabedoria. Sendo sábio e virtuoso o homem procurará seguir os preceitos da virtude e da divina lei da sabedoria, o que o transportará ao encontro da verdade. Por outro lado, o miserável ou indigente será infeliz porque sua alma é vazia, ou seja, improdutiva.

Outra questão valiosa que Santo Agostinho apresenta é sobre a fortuna: se o homem tiver bens, mas tiver uma alma indigente ou miserável será feliz? Ele responde dizendo que não será pela riqueza que o homem encontrará a felicidade ${ }^{[8]}$. Neste ponto, muitos se enganam, pois acreditam que ser rico é sinônimo de felicidade ou possuindo elevada quantidade de bens materiais terá uma vida completa de alegria. Santo Agostinho afirma que isto não é verdade. No mesmo capítulo, verso 30, de La Vida Feliz, ele elucida dizendo que a felicidade do homem virá pelo inverso da indigência, ou seja, virá pela alma plena e completa que conseguirá nivelar-se a sabedoria, a frugalidade, a temperança e a virtude.

Santo Agostinho apresenta outra questão: que outro valor o homem sábio precisa possuir para conduzir sua vida de forma equilibrada? O capítulo IV, versos 32-33, de La Vida Feliz diz que a sabedoria é simplesmente a moderação do espírito. Sem esta medida, o homem se lançaria ao exagero, ao prazer, a cobiça e a todas outras questões relacionadas ao mesmo gênero. Será à medida da alma que ajudará o homem sábio a encontrar o equilíbrio na vida, como afirma Santo Agostinho, no verso 32: "Luego la medida del alma está en la sabiduría.", ou seja, a medida do homem está na sabedoria.

Ainda, Santo Agostinho assegura que para o homem sábio viver com a verdade e seguindo as prescrições da virtude e da sabedoria, para que seja verdadeiramente feliz, é preciso que ele tenha um bem permanente, imutável e eterno. Este bem é Deus ${ }^{[9]}$. Ou seja, é feliz quem possui Deus.

Com esta afirmação verifica-se que todas as ações intelectuais do teólogo Santo Agostinho tiveram uma finalidade que era o próprio Deus. Os valores de Santo 
Agostinho estavam n'Ele e puderam ser vistos claramente em seu diálogo. O primeiro valor foi a sabedoria, pois, "[...] Deus é o princípio da sabedoria." (HOYLER, 1987:5). O segundo valor foram as virtudes, importantes para o homem possuir, para ser feliz. O terceiro valor foi a medida da alma que traria equilibrio para o homem nos exageros e nas faltas cometidas. O quarto valor era o homem encontrar a verdade e por fim, o quinto valor considerado o maior de todos e que traria a felicidade era o encontro do homem com Deus.

Enquanto Santo Agostinho não encontrou a verdade não descansou. Viveu incessantemente até encontrar a plenitude em sua vida que para ele era tão valorosa. Sua vida foi marcada por diversos valores, alguns implícitos e outros explícitos como a determinação, a coragem e a fé. Todos eles contribuíram para que o teólogo alcançasse a felicidade.

$\mathrm{Na}$ contemporaneidade muitos professores também exercitam tais valores. Dentro do imaginário, no sentimento e entendimento de cada um os valores são ensinados e praticados no exercício de cada dia.

\section{IMAGINÁRIO DOS PROFESSORES SOBRE OS VALORES E SUA RELAÇÃO COM A PRÁTICA PEDAGÓGICA}

Além dos valores destacados na tragetória de vida de Santo Agostinho, na parte introdutória deste trabalho, quatro outros valores foram citados por estarem relacionados às vivências escolares dos professores. Valores confirmados pela professora doutora Teresinha Rios como necessários para nortear o comportamento dos professores, quanto dos alunos.

Quais são os valores que os educadores jamais podem perder de vista e, inclusive, devem repassar aos seus alunos?

Para realizar a tarefa fundamental da educação, que é construir a humanidade, criando e socializando cultura, os educadores devem ter como horizonte a dignidade humana, a realização do bem comum, para o qual aponta a ética. Portanto, os 
princípios da ética - o respeito, a justiça, a solidariedade, o diálogo - devem ser os norteadores do comportamento tanto de professores quanto de alunos. (RIOS, 2004).

Entendo que estes valores são significativos para o mundo contemporâneo. Os exemplos do contexto social, moral, econômico e político têm deixado uma marca acinzentada nas jovens gerações. No meio deste cenário, encontram-se lares dilacerados e desestruturados e neles estão as crianças e os jovens alunos. Tudo isso gera uma preocupação adicional na formação das novas gerações, pois, a inversão dos valores é gigantesca e "[...] os valores, mesmo os permanentes, são atingidos pela mentalidade mudancista. $\mathrm{E}$ o questionamento se estende à própria civilização que se percebe como instável." (ENRICONE, 1992:34). Dentro deste contexto, o professor é fundamental e muitos docentes da contemporaneidade têm diariamente procurado fazer o melhor, mesmo quando discriminados e não valorizados pela sociedade.

Os relatos a seguir, refletem o posicionamento em relação as temáticas propostas para os educadores.

Prof. Marcos Antônio Gomes da Silva[10]

P: O que significa valor para você?

R: "Os valores estão ligados em todo âmbito geral, principalmente, no educacional. Valores éticos e valores morais, principalmente, na formação de um cidadão de caráter pensante, politicamente bem formado antes de qualquer coisa, ciente dos seus direitos e dos seus deveres."

P: Como você trabalha ou pode trabalhar na escola e na sala de aula o valor respeito?

R: "O respeito começa a partir da igualdade social, sem diferenças de classes, sem distinção de raça e opção sexual. Primeiro, respeitar o ser humano do jeito que ele é. Sua liberdade tem um limite de si próprio e do semelhante. Então, ao tratar o indivíduo com respeito e educação, 
você terá uma receptividade com educação e respeito. Se você trata com grito e autoritarismo e sem limites, a recíproca será a mesma."

Prof. Avilis ${ }^{[11]}$

P: O que significa valor para você?

$R$ : "São os conjuntos de elementos, que foram agregados na minha formação, ao longo dos meus anos de infância e adolescência, e que definiram o meu caráter, minha postura e minha atuação na sociedade."

P: Como você trabalha ou pode trabalhar na escola e na sala de aula o valor diálogo?

R: "Em princípio tenho que dizer que sou Paulo Freiriano. A questão do diálogo é fundamental na minha vivência, no meu trabalho. Se fugirmos disto, cairemos no monólogo, que é princípio da educação bancária; onde se pretende impor conhecimento, e, na verdade, é um trabalho de domesticação, de poda da liberdade. O diálogo é algo que tem de estar explícito na relação que se estabelece entre professor e aluno, para que possa haver uma horizontalidade de idéias, de comportamento e de conhecimento. A comunicação é fundamental, sem a comunicação não há educação. Contrário a isso, há monólogo, imposição e insatisfação. Porque tanto quem impõe, quanto quem recebe a imposição fica insatisfeito. Dialogando, consegue-se abrir portas e possibilita encontros."

Profa. Liete Ferraz ${ }^{[12]}$

P: O que significa valor para você?

R: "Valor é o que você dá para as coisas, mas, não financeiramente. Dentro da nossa perspectiva, aqui nesta entrevista, é o valor ao ser humano, o valor da aprendizagem, e o que você quer ser moralmente." 
P: Como você trabalha ou pode trabalhar na escola e na sala de aula o valor da solidariedade?

R: "É tentar fazê-los perceberem que precisam se ajudar. É ter respeito, não xingar, fazer a gentileza de pegar o papel no chão. Por exemplo: Pedimos para o aluno pegar o papel no chão. É um exemplo banal, então, ouvimos: "não foi eu que joguei", "porque tenho que pegar?", esta é a resposta básica. Já briguei muito com os alunos por conta disto. Eles não têm essa visão de solidariedade: "não foi eu que fiz, mas, eu posso ajudar alguém a melhorar o mundo". Não vai melhorar lá fora, porque é muito difícil, mas, é uma semente. Ajudar pegar alguma coisa, ajudar o menino machucado, ajudar na aprendizagem o cara que está com dificuldade, sentar junto, ensinar. Eles não fazem isto. É a cultura do individualismo mesmo! É a cultura bem capitalista, "eu quero, eu primeiro". Infelizmente, o mundo lá fora é assim. Sempre batemos na mesma tecla: se a família em casa, não tem essas bases, nós não conseguiremos. Eles não são solidários. São solidários, só entre si mesmos."

Profa. Miriam Aparecida Maltoni ${ }^{[13]}$

$\mathrm{P}: \mathrm{O}$ que significa valor para você?

R: "Valor é tudo aquilo que você pode passar de bom. No caso, como pedagoga, professora, são os princípios de cidadania, amor ao próximo, caridade, benevolência e amizade. Todos os direitos e deveres que $o$ cidadão tem. Tudo para mim é você passar valores e princípios, e todos esses princípios e todos os valores que você tem de bom para passar para um adolescente, principalmente, na escola. Nós educadores estamos aqui justamente para podermos passar esses valores para formação de cidadãos fortes para o nosso país e que tenham realmente uma consciência de cidadania." 
Profa. Ruth de Souza ${ }^{[14]}$

P: O que significa valor para você

R: "Como professora aposentada acredito que valores sempre serão importantes em todas as épocas. Eles são as virtudes que devem ser inerentes a todos os seres humanos. Refiro-me aos valores éticos e morais, tais como a justiça, a caridade, solidariedade, honestidade, compaixão, perdão, diálogo, tolerância cristã, renúncia, paciência, humildade, liberdade e verdade. Esses valores devem constituir o alicerce e os pilares de toda a sociedade. Devem servir de bússola no nosso caminhar. Os valores éticos e morais são os princípios de justiça, do progresso, da democracia, que devem estar embutidos e cultivados na estruturação da sociedade e da família."

P: Como você trabalha ou pode trabalhar na escola e na sala de aula o valor justiça?

R: "Praticando-a em primeiro lugar. Ao ensinar justiça temos que impor limite. Ensiná-los a somar, dividir, multiplicar na matemática da vida. Nesses termos, não serão admissíveis atos que venham afetá-los tais como calúnias, privar de algo que o aluno tenha direito, esconder alguma informação, ou ainda, descriminá-lo por algum fator de preconceito. $A$ justiça pode ser aplicada e cultivada no dia a dia no relacionamento, no trabalho, nos estudos, dentro da sala de aula, no intervalo e inclusive entre os colegas professores, que devem ser os maiores representantes e baluartes desta e demais virtudes."

\section{CONSIDERAÇÕES FINAIS}

Inicialmente, o que observamos é que os valores fundamentais foram construídos ao longo da história pelo próprio homem e ele mesmo os segue. A modificação destes valores ocorreu devido suas priorizações, caracterizações, questões culturais, questões econômicas e questões políticas de acordo com cada período histórico. Não 
há normas e regras fixas para as novas caracterizações dos valores. De acordo com a época e o crescimento da sociedade, novas questões foram sendo impostas para corresponder aos reclamos dos indivíduos, ou seja, espera-se que o resultado destas atribuições cause modificações nas suas ações, atitudes e no comportamento para melhor se adequar ao meio em que está inserido. Em seu meio, o homem troca experiências e aprende novas questões com seus pares, podendo ou não agregar valores.

Nesta direção, pergunta-se: Qual a importância de se refletir sobre a prática dos valores na escola, neste contexto da contemporaneidade?

Para Aristóteles (2007), todas as atividades humanas almejam algum bem e a maior delas é a felicidade. Verificamos que os professores entrevistados buscam ser felizes mesmo sendo criticados e desacreditados. Felizes por que fazem o que gostam e por terem esperança que o amanhã poderá ser melhor: " [...] então, vou dizer de forma bem clara que a educação do nosso país tem jeito, e a pedagogia que é colocada hoje na contemporaneidade tem jeito. É só arregaçar a manga e trabalhar. É através do trabalho contínuo que vamos conseguir resolver os problemas sociais, educacionais, e, inclusive, passar os valores familiares necessários dentro de uma escola." (profa. Miriam).

Esta esperança está subentendida na voz da professora e confirmada pelo sociólogo Bauman (1997) quando diz que a era pós-moderna pode simbolizar o desabrochar de um novo tempo ético e não um crepúsculo para a ética. Um novo começo, um novo renascer de uma visão dos valores sem ilusões, liberto da falsa consciência, das aspirações irreais e dos objetivos irrealizáveis.

Segundo Reale (1993), Sócrates deixou claro que tudo que é bom e justo são virtudes e as virtudes provêm do conhecimento. De posse da sabedoria o homem torna -se virtuoso e terá menos chances de errar.

Na Idade Média, a questão da felicidade foi pontuada por Santo Agostinho em sua obra "La vida feliz" que evidenciou que era importante que o homem cultivasse 
virtudes se quisesse ser feliz, todavia, era preciso "crer para entender e entender para crer" (Agostinho, 1999). Para ele o aprendizado vinha do interior do homem, por inspiração divina.

Puig (2007) diz que os valores se sobressaem na ordem da afetividade. Dificilmente fica-se apático diante de algum fato que acontece. Os princípios caridade e solidariedade têm exigido dos professores um esforço dobrado. Por mais intenso que sejam os apelos diante das questões catastróficas divulgadas continuamente pelos diferentes tipos de mídia, ainda assim, são valores que precisam serem constantementes trabalhados em sala de aula, visto a individualidade e a influência que o mundo presente tem provocado nos estudantes: “ [...] eles não tem visão de solidariedade. [...] ajudar pegar alguma coisa, ajudar o menino machucado [...] eles não fazem isto. É a cultura do individualismo mesmo! É a cultura bem capitalista "eu quero, eu primeiro". Infelizmente, o mundo o mundo lá fora é assim. Sempre batemos na mesma tecla: se a família em casa, não tem essas bases, nós não conseguiremos. Eles não são solidários. São solidários, só entre si mesmos. " (profa. Liete).

A fala da professora reforça o pensamento de Lipovetsky (2005) quando afirma que na contemporaneidade o homem se nega aos valores. Hoje, se configura uma ética que propaga o direito da individualidade, da boa vida, da autonomia, da felicidade e da satisfação pessoal, mantendo apenas alguma tolerância no convívio social. Os veículos de comunicação, a mídia, formam a opinião pública e ditam as normas de consumo e de comportamento, substituindo à religiosidade e à ética com informações pontuais, rápidas e sem rodeios. $O$ valor está naquilo que se apresenta como real.

É sabido que o exercício de educar não é fácil, mas os professores têm mostrado que é possível apesar das suas limitações. Reconhecem que na contemporaneidade se não ensinarem algo que faça a diferença a seus alunos, talvez, ninguém mais o faça. Os professores sabem da importância dos valores na formação dos alunos e entendem que não será pela imposição que alcançarão os objetivos. Para Bauman (1997), os valores precisam ser vistos com outro olhar e com uma nova forma de pensar e praticar. Entrementes, cada valor com as suas características, de acordo com a época, cultura e o regime político. Se os alunos que deixam a escola não têm 
um comportamento desejável, em nenhum momento poderão culpar os professores. Cada aluno é livre para escolher o caminho que quer seguir, mesmo que esse seja o mais doloroso.

Por outro lado, é preciso apoiar os professores na causa pelo ensino pautado nos valores, pois são eles que dentro da escola dirigem e ensinam futuros cidadãos a sobreviverem e viverem dentro da sociedade.

\section{REFERÊNCIAS}

AGOSTINHO, Santo. Confissões. Coleção os Pensadores. Trad. J. Oliveira Santos, A. Ambrósio de Pina. São Paulo: Nova Cultural, 1999.

A vida feliz. Tradução, introdução e notas de Ir. Nair de Assis, csa. São Paulo: Paulinas, 1993.

La vida feliz. Trad. Victorino Capanaga, OAR. Disponível em:< http://www.augustinus.it/spagnolo/felicita/index2.htm >. Acesso em: 16 setembro 2018.

Contra Acadêmicos. Tradução e prefácio de Vieira de Almeida. Coimbra: Biblioteca Filosófica, 1957.

ARISTÓTELES. Ética a Nicômaco. Trad. Pietro Nassetti. São Paulo: Martin Claret, 2007.

ARANHA, Maria Lúcia de Arruda; MARTINS, Maria Helena Pires. Introdução à filosofia. 2 ed. São Paulo: Moderna, 1993.

BAUMAN, Zygmunt. Ética pós-moderna. São Paulo: Paulus, 1997.

DUROZOI, Gerald; ANDRE, Rouse. Dicionário de filosofia. Trad. Marina Appenzeller. Campinas: Papirus, 1993. 
ENRICONE, Délcia. Valores no processo educativo. 2. ed. Porto Alegre: Sagra Luzzato, 1992.

HOYLER, Sandra H. L. Valores e Educação na História e no Imaginário de Oito Professores de São Paulo. Dissertação de Mestrado. Universidade Nove de Julho, UNINOVE, 2009. p.75.

HOYLER, Siegfried. Conquistando a felicidade. São Paulo: Helen, 1987.

LIPOVETSKY, Gilles. A sociedade pós moralista. 0 crepúsculo do dever e a ética indolor dos novos tempos democráticos. Trad. Armando Braio Ara. Barueri: Manole, 2005.

MACINTYRE, Alasdair. Depois da Virtude. Trad. Jussara Simões. Bauru: EDUSC, 2001.

NOSELLA, Paolo. Ética e pesquisa. Educação \& sociedade: revista de ciência da educação/ Centro de Estudos Educação e Sociedade - Vol.29, n.102, p.255-273, jan./abr. São Paulo: Cortez, 2008.

PALACIOS, Pelayo Moreno. O estamento da verdade no contra acadêmicos de Agostinho. Tese de Doutorado - Faculdade de Filosofia, Letras e Ciências Humanas da USP, São Paulo, 2006. Disponível em: <file://C:/Users/sandra/Downloads/tese_pelayo_moreno_palacios.pdf.> Acesso em: 16 outubro 2018.

PUIG, Josep Maria; ARAÚJJ, Ulisses; ARANTES, Valéria Amorim (Org.). Educação e valores. São Paulo: Summus, 2007.

REALE, Giovanni. História da filosofia antiga I: das origens a Sócrates. Trad. Marcelo Perini. São Paulo: Loyola, 1993.

REIS, B. V. Émilien. O Conceito de Virtude no Jovem Agostinho: Evolução ou Revolução? Dissertação de mestrado. PUC, Porto Alegre: 2006. 
RIOS, Teresinha Azerêdo. Compreender e Ensinar: ética e avaliação. 2004.Entrevista escolainterativa.Disponivelem:<https://www2.escolainterativa.com.br/canais/19_impr essao_pedagogica/IP/IP_39.pdf >. Acesso em: 16 setembro 2018.

1. Mestre, Professor titular no Departamento de Pedagogia do Centro Universitário Estácio.

2. Pós-Doutor em Administração de Empresas, Doutor em Educação Currículo, Mestre em Gestão de Saúde e Meio Ambiente e Mestre em Ciências, Professor Titular no Departamento de EaD do Senac-SP.

3. ${ }^{1}$ REIS, B. V. Émilien. O Conceito de Virtude no Jovem Agostinho: Evolução ou Revolução? Porto Alegre: PUC, 2006. Dissertação de mestrado.

4. L A vida feliz: Cap. II, verso 7.

5. C.Ac. I, 9, 25. "Nam cum beati esse cupiamus, sive id fieri non potest nisi inventa, sive non nisi diligenter quaesita veritate; postpositis caeteris omnibus rebus, nobis, si beati esse volumus, perquirenda est".

6. A vida feliz: cap. II verso 8 .

7. La Vida Feliz: cap. IV, verso 25.

8. Idem, cap. IV, verso 28.

9. Afirmação escrita no capítulo II, verso 11, da obra La Vida Feliz:.

10. Graduado em letras pela Pontifícia Universidade Católica de São Paulo - PUC, Cinema na FAAP, Pedagogia pela UNIBAN, e Mestrando em semiótica na PUC. Onze anos de docência nas disciplinas de Português e Inglês. Atuo como vice-diretor, coordenador e diretor da escola no suporte pedagógico há oito anos.

11. Graduado em educação artística, pela Faculdade de Belas Artes em São Paulo e Especialista em Arte e Educação, Faculdade Paulista de Artes do Ensino do Magistério Superior pela PUC.Vinte anos de docência em Educação Artística. Avilis é Pseudônimo.

12. Graduada em Biologia pela OSEC, atualmente, UNISA e Pedagogia pela UNIBAM. Vinte anos de docência como professora de Ciências e Biologia. 
13. Graduada em Jornalismo na Alcântara Machado e Cásper Líbero, Estudos Sociais e História na Uniban e dois anos de Pedagogia na IBEP. Especialista em VDCA (Violência Doméstica contra Crianças e Adolescente) na USP Mestranda em Literatura Africana - USP.

14. Graduação em Pedagogia pelo Instituto de Educação Dr. Julio Prestes de Albuquerque, Sorocaba - SP, e Ciências, pela Faculdade de Ciências e Letras, Nossa Senhora do Patrocínio em Itu - SP. Especialização em Aperfeiçoamento e Administradores Escolares pelo Instituto de Educação Dr. Julio Prestes de Albuquerque em Sorocaba - SP. Vinte e cinco anos de docência na escola pública primária.

Enviado: Janeiro, 2019.

Aprovado: Fevereiro, 2019. 